\section{SMGr\&up}

\section{SM Deantistry Journal}

\section{Article Information}

Received date: Apr 13, 2017

Accepted date: Aug 17, 2017

Published date: Aug 21, 2017

\section{${ }^{*}$ Corresponding authors}

Gabriela Caldeira Andrade Americano, Department of Preventive and Community Dentistry, State University of

Rio de Janeiro, Brazil,

Tel: +55 (21) 2868-8272; Email:

americanogabriela@gmail.com

Distributed under Creative Commons CC-BY 4.0

\title{
Dentigerous Cyst Involving Permanent Incisor: A Case Report
}

\author{
Mariana Salazar, Mariana Canano Séllos, Gabriela Caldeira Andrade Americano, \\ Mariana Pires da Costa, Mirian de Waele Souchois de Marsillac, Vera Campos \\ Department of Preventive and Community Dentistry, State University of Rio de Janeiro, Brazil
}

\section{Abstract}

Background: This paper aims to describe a case report about dentigerous cysts related to trauma in the primary teeth.

Case report: An eight-year-old boy attended the Pediatric Dental Trauma Clinic. He had a delay in the eruption of the tooth 11 and when he was four years old suffered a trauma in the tooth 51 . The radiograph showed a dentigerous cyst involving the tooth 11 . The lesion was treated through enucleation and the permanent tooth erupted.

Conclusions: A correlation was observed between the dentigerous cyst, trauma in the deciduous incisor and the successor teeth. Early diagnoses as well as clinical and radiographic follow-ups of traumatized primary teeth are important to minimize possible sequelae in the successor teeth.

\section{Introduction}

Traumatic dental injuries should be treated as an emergency. The diagnosis of the injury extent in the deciduous teeth must be done quickly and accurately, because these injuries may affect crowns or roots of the developing successor teeth [1]. Parents should be informed of the importance of dental appointments after traumas, because detailed clinical and radiographic exams are needed to determine the diagnosis and the most appropriate clinical treatment [2,3].

Traumas in the primary teeth, independently of etiologies or types, can be followed by pulp hyperemia which may revert completely or lead to pulp necrosis [4]. The most common sequelae in the primary teeth due to traumas are crown discoloration, pulp necrosis, pathological root resorption related to pulp inflammation, ankyloses, pulp canal obliteration or early tooth loss $[5,6]$. The correlation between the development of dentigerous cysts, periapical inflammations of the deciduous teeth and crowns of the successor teeth has also been reported [7,8].

Dentigerous cysts (follicular) are pathologies of odontogenic origin which arise during or after the enamel development of the permanent teeth [9]. The delay in the eruption of the permanent teeth accompanied by swelling suggests the presence of dentigerous cysts. These cysts are most common in Caucasian men in the first and second decades of life and affect third molars, upper canines, lower premolars [10-12]. Radiographically, they are radiolucent, unilocular and welldelimited areas associated with crowns of unerupted teeth as well as may reach the size of 4 to $5 \mathrm{~cm}$ of diameter within a period of 3 to 4 years [13]. The diagnosis of dentigerous cysts is determined through the histopathological exams [7,9]. The treatment is usually dictated by the lesion size [14]. Major lesions, that involve bone loss and have fracture risks, should be treated through cystostomy. In this procedure, the cyst is opened to create a communication between the cystic cavity and the oral cavity. Minor injuries should be treated through enucleation or cystectomy, which cysts are removed completely. After treatment, the eruption follow-up of the permanent teeth is required $[15,16]$.

This paper aims to describe a case report about dentigerous cysts related to trauma in the primary teeth. It emphasizes the diagnosis and the conservative approach of dentigerous cysts.

\section{Case Report}

An eight-year-old boy attended the Pediatric Dental Trauma Clinic accompanied by his mother. The main complaint was the delay in the eruption of the permanent right upper central incisor. During the anamnesis, the mother told us the child fell from one's own height when he was four years old, which resulted in the primary right upper central incisor intrusion. Through a clinical exam, it was realized that the tooth 51 had a prolonged retention, crown discoloration as well as a firm swelling during palpation located at the apex region (Figure 1). The upper occlusal radiograph showed a radiolucent, unilocular and well-delimited area with a width of approximately $3 \mathrm{~cm}$, involving the permanent right upper central incisor (Figure 2). The lesion was treated through enucleation under local anesthesia to preserve the associated permanent teeth (Figures 3 and 4). 


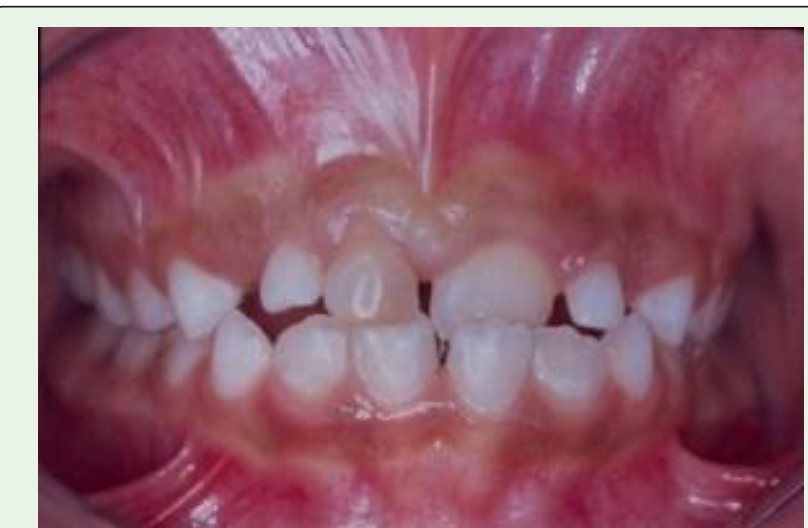

Figure 1: Initial clinical aspect.

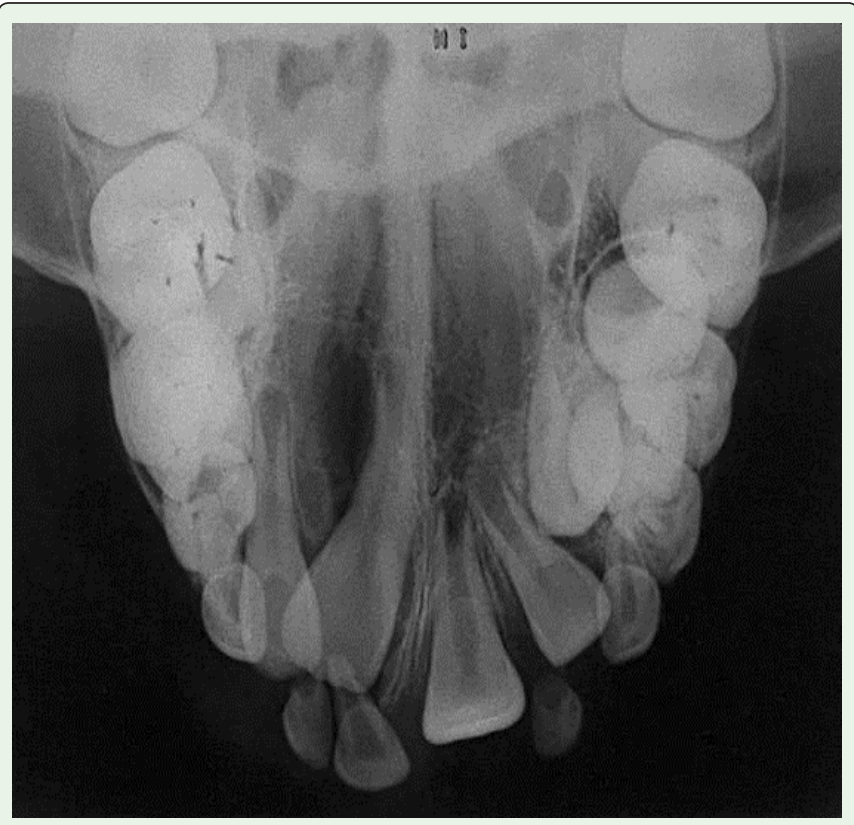

Figure 2: Initial radiographic aspect.

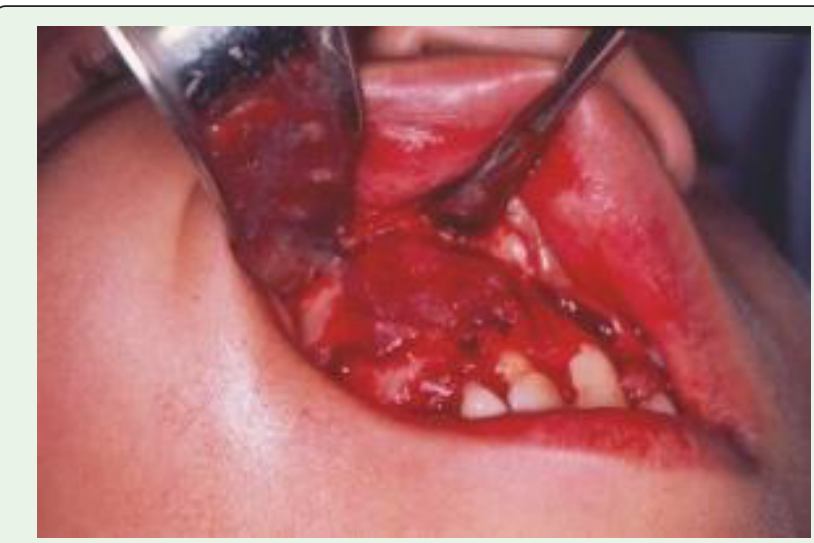

Figure 3: Enucleation of the cystic lesion.

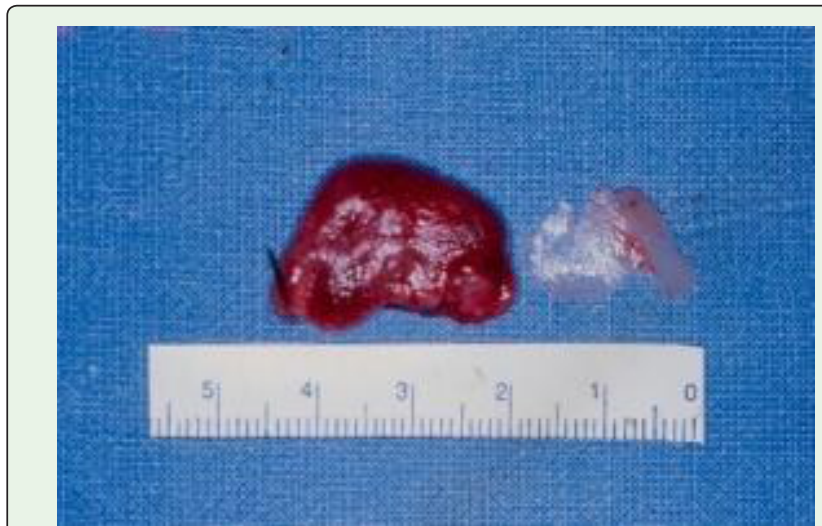

Figure 4: The cystic lesion and part of the cortical bone.

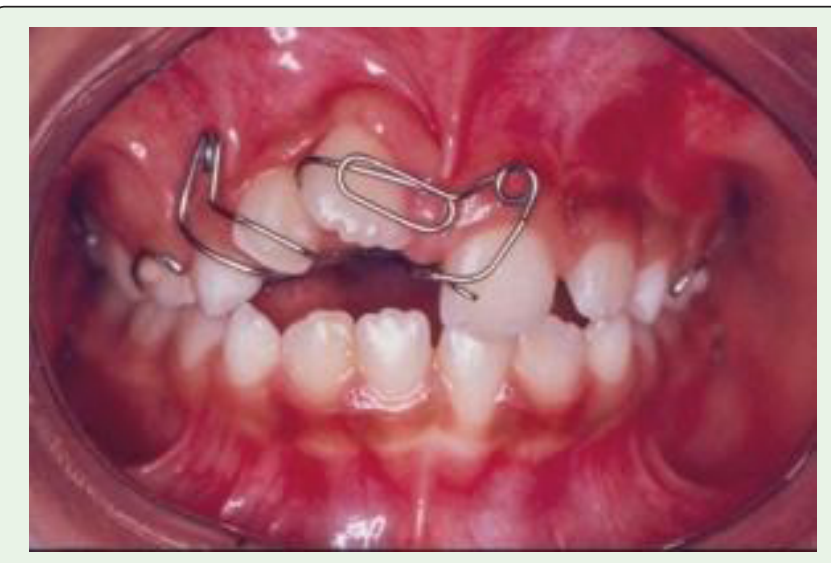

Figure 5: Removable appliance for the upper incisors alignment after crossbite correction.

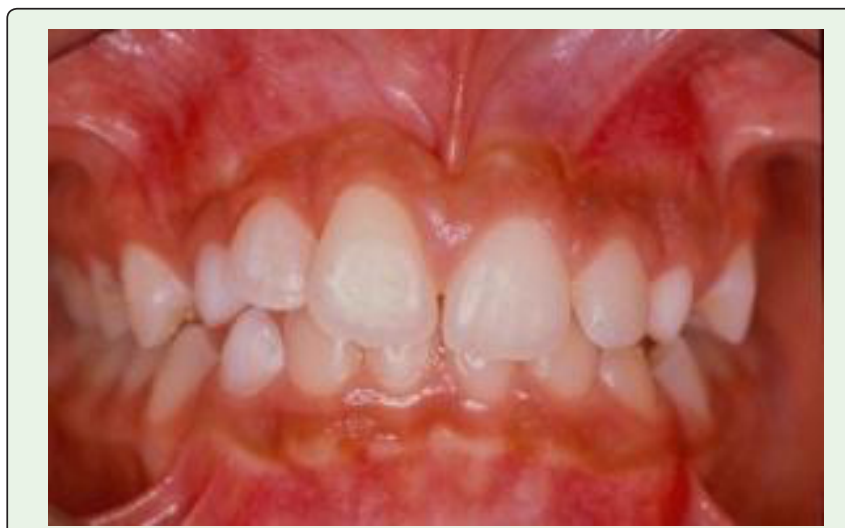

Figure 6: Final clinical aspect.

The histopathological exam was done confirming the diagnosis of a dentigerous cyst. The tooth 11 erupted spontaneously and ectopically six months later. Orthodontic treatment was applied to correct the tooth displacement (Figure 5). The follow-up of the patient through clinical and radiographic exams was carried out until the total eruption of the upper incisors (Figures 6 and 7). 


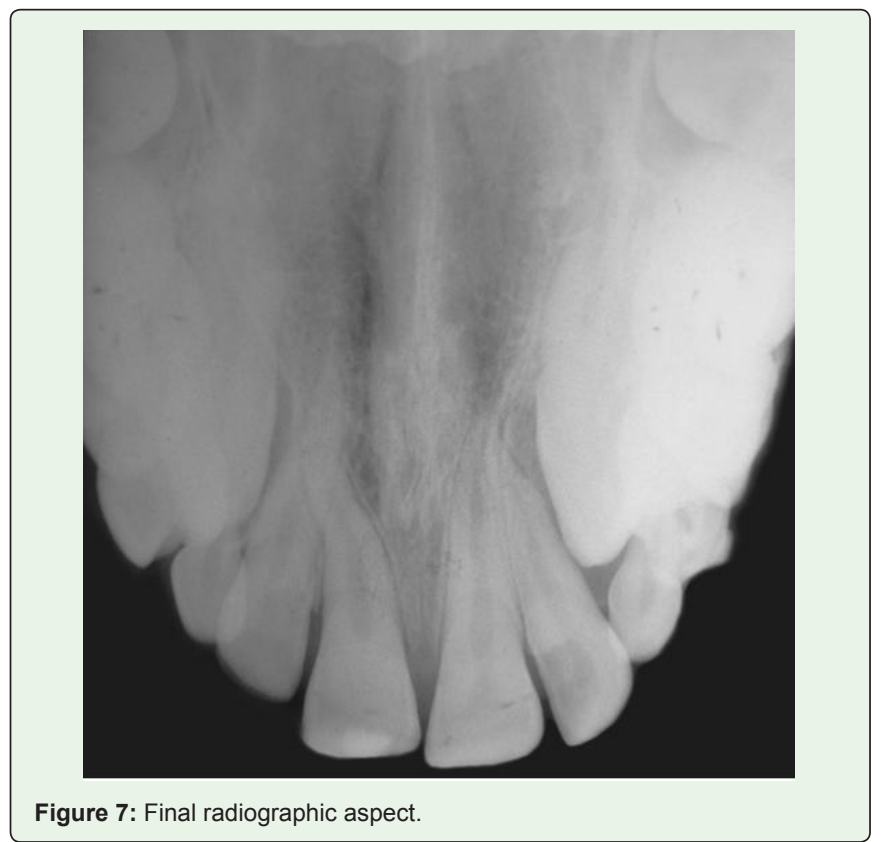

\section{Discussion}

Dentigerous cysts are defined as a cystic cavity originated from the accumulation of fluid between the reduced enamel epithelium and the crown of an unerupted tooth, attached to the cemento-enamel junction. The pathogenesis is still controversial. A possible origin is related to an inflammatory process that may affect a developing tooth resulting in proliferation of the reduced enamel epithelium [17]. The correlation between dentigerous cysts, trauma in the deciduous teeth and crowns of the successor teeth has been reported $[7,8,10,18,19]$. In the present case report, the impact force of trauma in the primary incisor could have led to odontogenesis disturbances on the successor tooth.

The dentigerous cyst diagnosis after four years of trauma in the primary incisor emphasizes the importance of clinical and radiographic follow-ups until the total eruption of the successor teeth. Therefore, guardians should be aware of the importance of reporting any dental trauma episode and the follow-up of the traumatized tooth. Thus, it can be possible to avoid or minimize potential sequelae in the deciduous or permanent teeth.

As minor cysts can be treated through enucleation [14], this technique was chosen as treatment. The location and size of the lesion allowed its complete removal, the maintenance of the permanent tooth and the primary closure of the cavity. The treatment was multidisciplinary (Pediatric Dentistry, Radiology, Bucomaxillofacial Traumatology and Orthodontics) and lasted three years. The cooperation of the parents and the patient in attending follow-up appointments was also paramount to the treatment success.

In conclusion, a correlation was observed between the dentigerous cyst, trauma in the deciduous incisor and the successor teeth. Early diagnoses as well as clinical and radiographic follow-ups of traumatized primary teeth are important to minimize possible sequelae in the successor teeth.

\section{References}

1. Jácomo DRES. Campos V Prevalence of sequelae in the permanent anterior teeth after trauma in their predecessors: a longitudinal study of 8 years. Dent Traumatol. 2009; 25: 300-304

2. Andreasen JO, Ravn JJ. Effect of traumatic injuries to primary teeth on their permanent successors II. A clinical and radiographic follow-up study of 213 teeth. Scand J Dent Res. 1971; 79: 284-294.

3. Wendt FP, Torriani DD, Assunção MCF, Romano AR, Bonow MLM, et al.Traumatic dental injuries in primary dentition: epidemiological study among preschool children in South Brazil. Dent Traumatol. 2010; 26: 168-173.

4. Pugliesi DMC, Cunha RF, Delbem ACB, Sundefeld. ML Influence of type of dental trauma on the pulp vitality and the time elapsed until treatment: a study in patients aged 0-3 years. Dent Traumatol. 2004; 20: 139-142.

5. Carvalho V, Jacomo DR. Campos V. Frequency of intrusive luxation in deciduous teeth and its effects. Dent Traumato. 2010; 26: 304-307.

6. Diab M, Elbadrawy HE. Intrusion injuries of primary incisors. Part III: effects on the permanent successors. Quintessence Int. 2000; 31: 377-384.

7. Seddon RP, Fung DE, Bernard KM, Smith PB. Dentigerous cysts involving permanent incisors: four cases reports. Int J Paediatr Dent. 1992; 2:105-111.

8. Sannomiya EK, Nogueira MQ, Diniz MC, Pacca FOT, Dalben GS. Traumainduced dentigerous cyst involving the anterior maxilla. J Dent Child. 2007 74: 161-164.

9. Kramer IRH, Pindborg JJ, Shear M. The WHO histological typing of odontogenic tumours. A commentary on the second edition. Cancer. 1992; 70: $2988-2994$

10. Killian CM, Leventhal PH, Tamaroff JL. Dentigerous cyst associated with trauma to a primary incisor: a case report. Quintessence Int. 1992; 23: 683686.

11. Selvamani M, Donoghue M, Basandi PS. Analysis of 153 cases of odontogenic cysts in a South Indian sample population: a retrospective study over a decade. Braz Oral Res. 2012; 26: 330-334.

12. Demiriz L, Misir AF, Gorur DI. Dentigerous cyst in a young child. Eur J Dent. 2015; 9: 599-602.

13. Bhardwaj B, Sharma S, Chitlangia $P$, Agarwal $P$, Bhamboo $A$, et al. Mandibular dentigerous cyst in a 10 -year-old child. Int $\mathrm{J}$ Clin Pediatr Dent. 2016; 9; 281-284.

14. Jena AK, Duggal R, Roychoudhury A, Parkash H. Orthodontic assisted tooth eruption in a dentigerous cyst: a case report. J Clin Pediatr Den. 2004; 29: 33-35.

15. Peterson LJ, Ellis E, Hupp JR, Tucker MR. Cirurgia Oral e Maxilofacial Contemporânea. $4^{\text {th }}$ edn. Rio de Janeiro: Elsevier. 2005.

16. Deboni MC, Brozoski MA, Traina AA, Acay RR, Naclério-Homem MG. Surgical management of entigerous cyst and keratocystic odontogenic tumor in children: A conservative approach and 7-year follow-up. J Appl Oral Sci. 2012; 20: 282-285.

17. Benn A, Altini M. Dentigerous cyst of inflammatory origin: A clinicopathological study. Oral Surg Oral Med Oral Pathol Oral Radiol Endod. 1996; 81: 203-209.

18. Naclério H, Simões WA, Zindel D, Chilvarquer I, Aparecida TA. Dentigerous cyst associated with an upper permanent central incisor: case report and literature review. J Clin Pediatr Dent. 2003: 26: 187-192.

19. Sharma D, Garg S, Singh G, Swami S. Trauma-induced dentigerous cyst involving an inverted impacted mesiodens: case report. Dent Traumatol. 2010; 26: 289-291. 